\title{
Molecular diagnosis of some common genetic diseases in Russia and the former USSR: present and future
}

\author{
V S Baranov
}

\begin{abstract}
The current state of molecular diagnosis of some common genetic diseases, including cystic fibrosis, Duchenne muscular dystrophy, haemophilia $A$ and $B$, phenylketonuria, and thalassaemia, in Russia and elsewhere in the former USSR is reviewed. Data on carrier detection and prenatal diagnosis are presented and some objective problems and obstacles hampering efficient molecular diagnosis in Russia are discussed. The necessity for molecular diagnosis of some other inherited diseases (for example, von Willebrand's disease, Martin-Bell syndrome, polycystic kidney disease, Huntington's disease, and myotonic dystrophy) is stressed. The need for establishing new diagnostic centres dealing with the most common diseases, as well as rare genetic diseases, is substantiated. Perspectives on the implementation of new molecular methods and new technical approaches (preimplantation embryo diagnosis, fetal cells selected from maternal blood) are briefly outlined. (f Med Genet 1993;30:141-6)
\end{abstract}

The recent disintegration of the former USSR into 15 independent states has caused tremendous disorganisation, not only in the economy as a whole but in all other fields of social life, including health services and medical genetics in particular. The devastating consequences of this largely bloodless revolution for medical genetics stem primarily from pre-existing drawbacks in the organisation of medical genetic services throughout the former gigantic multinational country. Monopolisation of science by two capital cities, Moscow and Leningrad (St Petersburg since September 1991 ), in conjunction with a very unequal and generally rather low level of routine medical genetic counselling and laboratory diagnosis, can primarily be held responsible for this.

An urgent programme of promotion and improvement of public medical genetic services in the USSR was elaborated and officially approved by the special session of our Ministry of Health early in 1988. In spite of definite progress in the screening of newborns for some inherited diseases, organisation of numerous (about 115) local medical genetics committees, inter-regional medical genetics centres (about 25), as well as the creation of an All-Union Centre for Medical Genetics, incorporating the former Institute of Medical Genetics and a new Institute of Clinical Genetics in Moscow, modest funding and the absence of hard currency still significantly hampers progress in medical genetics throughout the country. Fortunately, since January 1989, scientists from the most advanced laboratories in the USSR (mainly from Moscow and Leningrad and a few from other capitals of the Union Republics) have gained access to hard currency through a new State Scientific Programme (Human Genome), headed by academician A A Baev, and launched by the Academy of Sciences.

Participation in this programme during 1989 and 1990 has provided at least some scientists with grants partly paid in hard currency and thus has enabled them to acquire necessary equipment and reagents indispensable for molecular analysis. It is still too early to estimate the significance of our Human Genome Programme as a whole, but its important impact on medical genetic studies in this country is quite obvious and has been highly appreciated. Over 50 different medical genetics projects were funded through the Human Genome Programme in 1991.

The principal goal of the present paper is to give an up to date review of molecular diagnosis for widespread genetic diseases in Russia and the former USSR, with special emphasis on the major problems facing our specialists in medical genetics dealing with molecular studies.

As several different laboratories are usually involved in molecular studies of the same common genetic disease, each unit will be considered separately, indicating the participation of each laboratory dealing with a particular disease.

\section{Cystic fibrosis}

Molecular studies of cystic fibrosis (CF) were launched in 1985 after the author's one month visit to Great Britain as a WHO student. Professor Bob Williamson provided recently 
discovered DNA probes which enabled Southern blot analysis of RFLPs to be established, first at the Institute of Experimental Medicine and, since 1987, in a newly organised laboratory for prenatal diagnosis of inherited diseases at the Institute of Obstetrics and Gynecology, Academy of Medical Sciences, St Petersburg. The latter laboratory acquired the status of an All-Union Centre for prenatal diagnosis of CF in 1989.

Patterns of allelic polymorphisms in CF have been analysed by collaborative studies in native populations from six different regions of the European part of the former USSR. Significant differences were discovered in the Lithuanian population (Met, D7S23) as well as the southern Slavonian populations of Ukrania and Krasnodar (D7S23). ${ }^{1}$

CF studies were intensified after identification of the gene and the discovery of the major $\Delta \mathrm{F} 508$ mutation. According to our data the frequency of $\Delta F 508$ in native populations from the European part of the country varies significantly (from $30 \%$ in Moldova to $69 \%$ in Ukrania) being, on average, around $50 \%$ for CF patients in the north-west and central parts of Russia. ${ }^{2}$

Large scale testing of the $\Delta \mathrm{F} 508$ mutation has become possible after adopting the PCR technique for dried blood spots on filter paper. ${ }^{3}$ Some other interesting innovations of PCR techniques have been suggested by $E$ Schwartz's group at the Institute of Nuclear Physics in St Petersburg. ${ }^{4}$

Pilot screening studies in St Petersburg (E Schwartz, Russian Centre for Molecular Diagnosis of Inherited Diseases) and in Ukrania (L Livshitz, Institute of Molecular Biology and Genetics, Kiev) favour a relatively low frequency of $\Delta F 508$ among newborns (1:40). The other major mutations of the CFTR gene known to be quite common in western populations (G551D, R553X, R334W, W1282X, $\mathrm{R} 551 \mathrm{X}, 1716+12 \mathrm{~T} \rightarrow \mathrm{C}$ ) are detected only occasionally (1 to $3 \%$ ) in our CF patients. ${ }^{5}$

However, CFTR gene mutation 3732delA (exon 19), recently found in southern France, was detected in almost $7 \%$ of Russian CF chromosomes in our collaborative studies with M Dean's laboratory (NIH, NCI, Frederick, USA). ${ }^{6}$ Moreover, 1677 delTA, originally discovered by our group ${ }^{7}$ in Georgia (Megrelia region) turned out to be a major mutation in the populations of the Black Sea Basin. Three more new CFTR gene mutations (E504Q exon 10 , W1282R exon 19, and S1196X) have been recently shown by SSCP analysis followed by direct sequencing.?

According to these data the search for new mutations of the CFTR gene in our CF patients might be highly productive. At least three different mutations, $\Delta$ F508, 1677delTA, and $3732 \mathrm{delA}$, might be used both for carrier detection and prenatal diagnosis of CF in Russia. These data are of special practical value as most of the families requesting prenatal diagnosis of $\mathrm{CF}$ in this country do not have a living index child and thus cannot be subjected to RFLP analysis.
Around 200 prenatal diagnoses for CF have been carried out so far in the St Petersburg Centre. In 40 cases this relied exclusively on molecular analysis, in 72 on molecular studies plus microvillar enzyme testing, and in the rest ( 88 cases) only on the latter. A diagnosis of CF has been made in 51 fetuses at risk and these pregnancies were terminated. ${ }^{8}$

Molecular analysis of CF is carried out in close collaboration with our centre in the Institute of Experimental Medicine, Academy of Medical Sciences, Laboratory of Biochemical Genetics (phenotype-genotype correlations, RFLP analysis ${ }^{910}$ ), in the Russian Centre for Molecular Diagnosis of Inherited Diseases (pilot screening programme, intragenic polymorphism studies), both in St Petersburg, in the Centre of Medical Genetics, Moscow (mutation identification $\left.{ }^{11}\right)$, and in the Institute of Molecular Biology and Genetics, Ukrania Academy of Sciences, Kiev. ${ }^{12}$

Identification of new major CFTR gene mutations, specific to our native populations, as well as RFLP analysis of new intragenic polymorphisms, such as the recently discovered highly polymorphic minisatellite DNA sequences in introns 6,8 , and $17 \mathrm{~b}$, is helping in more efficient application of molecular analysis in CF patients.

As this centre still remains a single unit in Russia, and even in the whole former USSR, for prenatal diagnosis of this very common genetic disease, the foundation of new molecular diagnostic centres dealing with high risk CF families is very urgent.

\section{Duchenne muscular dystrophy}

Molecular diagnosis of Duchenne muscular dystrophy (DMD) was started independently and almost simultaneously by two research groups, our laboratory in St Petersburg and O Evgrafov's group in Moscow (now Laboratory of Molecular Diagnosis at the Institute of Clinical Genetics).

Initial studies were carried out with intragenic and flanking DNA probes, generously donated by Drs Kay Davies and T Monaco (UK) as well as by Drs $L$ Kunkel and $M$ Koenig (USA). These studies were later supplemented with multiplex polymerase chain reaction (MPCR) for exon deletion detection in the dystrophin gene. Both carrier detection and prenatal diagnosis have been done by the two groups. According to our collaborative data, ${ }^{13}$ DNA analysis has been provided for 119 at risk families with at least one affected child, or with an affected close male relative of a woman at risk of being a heterozygous carrier. Most (about $80 \%$ ) of the families were represented by a sporadic case. MPCR for 11 different exons ascertained dystrophin gene deletions in $41 \%$ of our patients ( 49 out of the total 119). A relatively low deletion detection rate with the standard set of exons tested by MPCR, a somewhat unusual pattern of deletion distribution along the DMD cDNA, and a significant proportion of extensive deletions extending through the major part of the gene, substantiated possible population differences 
of DMD mutations in Russian patients compared with published collaborative data. ${ }^{14}$

More studies are already in progress both in St Petersburg and in Moscow to ascertain or to reject possible population diversity in the pattern of common deletions in the dystrophin gene and to study their population frequencies and vulnerability of each exon during germ cell proliferation and meiotic recombination.

Of 94 families, 76 were found to be informative by RFLP analysis. Carrier status was confirmed in 12 and excluded in 21 female relatives in 21 DMD families. Out of 22 prenatal diagnoses, eight affected fetuses were diagnosed prenatally by direct deletion testing or by RFLP analysis.

Meanwhile, both carrier detection and prenatal diagnosis of DMD are still far from a final solution in Russia. One of the possible approaches, not yet tried here so far, concerns RNA amplification supplemented with MPCR analysis of cDNA. ${ }^{15}$ Of special diagnostic value for at least some male fetuses at risk might also be the application of western blotting to muscle biopsies or direct immunocytochemical studies of dystrophin in muscle fibres. This approach might be of great benefit for the otherwise uninformative DMD families requesting prenatal diagnosis during the second trimester of pregnancy.

\section{Haemophilia A}

Molecular diagnosis of haemophilia A in Russia was started in 1987 by our research group in St Petersburg and by G Soloviev's group in the All-Union Haematological Centre (Moscow). DNA probes were kindly provided by Dr J-L Mandel (France) and Drs R Lawn and E Gitschier (USA). Over 200 at risk families have already been studied, most of them from Russia (130) and the rest from haemophilia centres in other states (Ukrania, Moldova, Belorussia, Uzbekistan etc).

Highly polymorphic flanking DNA (probe St 14/TaqI) and intragenic polymorphic sites HindIII (intron 19), BclI (intron 18), and $X b a \mathrm{I}$ (intron 22) were used both for population studies and diagnostic purposes. Some intragenic polymorphic sites were used for polymerase chain reaction detection. ${ }^{16}$

Frequencies of allelic polymorphisms studied for both intra- and intergenic probes in the Slavonian and Uzbekian populations were found to be very similar and closely resembled those in western European populations. Two unusual alleles of the St14/TaqI site have been discovered by our group in some Slavonian and Uzbekian samples. ${ }^{17}$

Carrier status has been confirmed in 43 and rejected in 49 close female relatives of the proband in 113 families under our supervision. Haemophilia $\mathrm{A}$ has been diagnosed prenatally in 18 out of 30 cases studied so far by our group. Several prenatal diagnoses by PCR have been carried out by the Moscow group in collaboration with their German colleagues. ${ }^{18}$ Mutation identification by SSCP analysis followed by direct sequencing of altered exons and amplification-mismatch detection studies of the factor VIII gene are now in progress.

\section{Haemophilia B}

Intragenic DNA probes available for RFLP analysis of the factor IX gene were kindly donated to the author by Professor G Brownlee (UK) in 1985. Southern blot RFLP analysis with these probes was later replaced by PCR for detection of intragenic polymorphic sites TaqI, XmnI (both in intron C), and HinfI/DdeI (intron A). Polymorphism identification was done with original sets of oligoprimers suggested in collaborative studies with G Solovijv's group in Moscow.

RFLP analysis of different native populations has shown an unusual allele (most probably a large insertion) in the HinfI/DdeI polymorphic site in two Uzbekian DNA samples.

Carrier status has been proved in 10 and rejected in six female relatives of affected men in 18 families at risk. An unusually large deletion extending through both neighbouring exons $\mathrm{G}$ and $\mathrm{H}$ has been discovered in one patient of Slavonian origin.

It should be mentioned that RFLP analysis is still informative in about 60 to $70 \%$ of at risk families. Thus, direct identification of mutations by means of SSCP analysis or by the amplification-mismatch detection technique is advisable. Both of these approaches are now in use in our laboratory.

\section{Phenylketonuria}

Large scale newborn screening programmes for phenylketonuria (PKU), either by the Guthrie test or by an automated fluorescent assay, was officially recommended by the Ministry of Health of the USSR in 1988. According to already available data the frequency of PKU in newborns varies between 1 in 5000 to 1 in 8000 in different regions, with an average of around 1 in 6000 (G Zuckerman, Institute of Medical Genetics, Minsk, Belorussia).

Molecular analysis of PKU in the USSR was initiated with the CDNA probe of the PAH gene, generously provided by $\mathrm{Dr} \mathrm{X}$ Woo (USA) to Dr V Kalinin (Laboratory of Molecular Genetics, Institute of Medical Genetics, Moscow). These studies were substantially helped later by the PCR method introduced in Russia by Dr E Schwartz (Russian Centre for Molecular Diagnosis of Genetic Diseases, St Petersburg). The fortunate availability of thermostable DNA polymerase from Thermus thermophilis, manufactured by the Institute of Nuclear Physics, Academy of Science, USSR (St Petersburg) considerably facilitated a quick spread of the PCR method throughout the country since 1988 .

RFLP analysis of the PAH gene in Russian Slavonians and in some other populations (Buryats) showed that the frequency of allelic polymorphisms for the polymorphic sites $M s p \mathrm{I}, E c o \mathrm{RI}$, and HindIII is similar in these populations and does not differ greatly from other European populations. ${ }^{19} \mathrm{New}$, efficient detection of point mutations by the limited 
elongation method has recently been suggested by this group in collaboration with Australian scientists. ${ }^{20}$

Allele specific hybridisation supplemented with direct sequencing of exon 12 of the $\mathrm{PAH}$ gene showed the mutation in codon 408 as well as the exon-intron splicing mutation to be predominant in Russian Slavonians (E Schwartz).

More detailed identification of PKU mutations in DNA samples from native USSR populations is now in progress in collaborative studies of E Schwartz's Centre with X Woo's laboratory at Baylor College (USA). ${ }^{21}$

Eight of 12 families at risk for PKU were found to be fully informative for the 408 mutation in our collaborative studies with the Centre; 11 families at risk requested prenatal diagnosis and PKU has been confirmed in three fetuses. These pregnancies were terminated.

\section{$\beta$ thalassaemia}

This genetic disease is confined to some southern republics of the former USSR, in particular Azerbaijan, Uzbekistan, and Tadjikistan, where carrier frequencies are estimated to be around $10 \%$ (G Solovjev). Molecular studies of $\beta$ thalassaemia were started in 1975 and were initially confined to mRNA analysis and its application to deletion detection in the $\beta$ globin gene (L Lymborskaya). Detailed molecular studies with more advanced techniques were undertaken by G Solovjev's group at the Scientific Research Haematological Centre in Moscow and by E Schwartz's Centre in St Petersburg. RFLP analysis in $32 \beta$ thalassaemia patients with a severe form of the disease showed 11 different haplotypes, one of which was encountered in half of all affected subjects. This particular haplotype was actually in strong linkage disequilibrium with mutations in codon 8 . Five different mutations of the globin gene were discovered in seven patients from Azerbaijan by PCR followed by direct sequencing of the amplification products. One of these mutations (deletion of a $G$ nucleotide between codons 82 and 83 ) was found for the first time. ${ }^{22}$ Oligoprimer sets suitable for allele specific amplification and thus for direct identification of $\beta$ globin gene mutations in the Azerbaijanian population have been suggested. ${ }^{23}$

Large scale screening of blood spots from pregnant women in Baku (Azerbaijan) has recently been undertaken and has resulted in the identification of 66 at risk families (A Kuliev, Institute of Medical Genetics, Moscow). Prenatal diagnosis of $\beta$ thalassaemia has been undertaken in 41 pregnant women and 14 fetuses homozygous for $\beta$ globin mutations diagnosed.

\section{Wilson's disease (hepatolenticular degeneration)}

While being quite infrequent (an average frequency in European populations of Russia is about 1 in 20000 ), WD deserves special atten- tion as for many years it has been thoroughly studied in the Laboratory of Biochemical Genetics, Institute for Experimental Medicine, in St Petersburg (Professor S Nejfakh and his successor Professor V Gaitzkhoki).

Identification and biochemical investigations of copper binding protein caeruloplasmin (CP) in Wilson's disease patients were later extended to CP mRNA and CP gene molecular analysis. ${ }^{24}$ However, quite unexpectedly for this group, these studies failed to disclose any mutations of the CP gene in patients and thus indicated that the CP gene is not involved by itself in Wilson's disease. The later assignment of $W D$ to chromosome 13 but not to chromosome 3 (where the CP gene is located) agreed with Neifakh's laboratory studies. Curiously enough, our in situ gene mapping with an original fragment of rat CP-DNA as a hybridisation probe disclosed a positive hybridisation signal not only on chromosome 3 (3q23-25, close to the transferrin gene) but also on chromosome 13 (13q23-24), that is, somewhere very close to the still unknown gene responsible for Wilson's disease. ${ }^{25}$ Thus the problem of the molecular nature of Wilson's disease is still awaiting a solution.

Meanwhile chromosome 13 is one of the genome units selected by our Human Genome Project for detailed molecular analysis. Identification of the gene for Wilson's disease is one of the urgent tasks for this project.

\section{$\alpha_{1}$ antitrypsin deficiency}

DNA analysis of $\alpha_{1}$ antitrypsin deficiency (AD) is confined to one laboratory (Laboratory of Biochemical Genetics, St Petersburg, V Gaitzkhoki) working in collaboration with Charles Coutelle's laboratory in Germany (Berlin). RFLP analysis was carried out in 659 patients with chronic non-specific lung disease and a substantial preponderance of the abnormal $\mathrm{Z}$ allele was found (N Monakhov). An unusual neutral mutation of the MaeIII site in exon 3 of the AT gene in 20 to $30 \%$ of normal subjects with the MI allele, as well as its linkage disequilibrium with the $\mathrm{Z}$ allele in $\mathrm{AD}$ patients, was discovered. An allele specific amplification system for direct detection of the common mutation in codon 342 of AD patients with the $\mathrm{Z}$ haplotype was elaborated and tested (A Schwartzman).

\section{Familial hypercholesterolaemia and other lipoprotein disorders}

Molecular analysis has been confined to 20 families with familial hypercholesterolaemia (A Schwartzman). No major mutations or rearrangements in the low density lipoprotein receptor gene have been reported so far. RFLP analysis of different polymorphic sites of the receptor gene in normal and affected subjects is in progress.

Correlation of particular genotypes of Apo CIII, Apo B100, and Apo Al genes with blood cholesterol lipoprotein levels in patients with cardiac ischaemic disease and in the general population is being studied by E Schwartz's 
Centre in St Petersburg ${ }^{26}$ and N Mertvetzov's group in the Institute of Bio-organic Chemistry in Novosibirsk. A simple approach based on PCR mediated site directed mutagenesis has been suggested for the identification of the common mutation in codon 3500 of the apo $\mathrm{B} 100$ gene. $^{27}$

\section{Conclusions}

As might be inferred from these data, there are now at least seven different laboratories in Russia dealing with the molecular analysis of around 10 different common genetic diseases.

Many more genetic diseases have recently become amenable to molecular studies by these groups owing to the generous donation of new DNA probes, while even more genetic disorders can be studied by the much more efficient and convenient PCR techniques. Good candidates for molecular studies in Russia include the following diseases: fragile $\mathrm{X}$ syndrome, polycystic kidney disease, myotonic dystrophy, von Willebrand disease (St Petersburg), Friedreich's ataxia, spinal muscular atrophy, Huntington's disease, some mucopolysaccharidoses, adrenogenital syndrome (O Evgrafov's laboratory at the Institute of Clinical Genetics in Moscow), in addition to some forms of diabetes (E Schwartz's Centre in St Petersburg).

Of these diseases fragile $\mathrm{X}$ mental retardation is of special practical and scientific interest. Application of new DNA probes generously provided by Drs Kay Davies and J-L Mandel have opened the way for efficient carrier detection and prenatal diagnosis of this syndrome. There are already over 20 diagnosed fra (X) families in St Petersburg and about 70 in Moscow. A programme of active clinical and laboratory search for new at risk families and their subsequent molecular analysis is already in progress.

The problem of identification of at risk families is urgent, not only for the fragile $\mathrm{X}$ syndrome but also for most of the diseases mentioned above and reflects the overall low level of medical genetic services in Russia. This stems both from inadequate medical genetic counselling and unsatisfactory (very limited and often inefficient) laboratory diagnostic services. Conspicuous advances in the molecular diagnosis of some common genetic diseases on the one hand and the rather primitive routine medical genetic services on the other, constitute an obvious paradox in medical genetics in Russia today. As a result, many at risk families already amenable to molecular analysis remain unknown and cannot benefit from molecular advances, while others who are already diagnosed are not properly informed about the possibility of prenatal diagnosis and carrier detection or cannot obtain proper treatment for their disease. Another consequence of this situation is overdiagnosis of some diseases, for example, cystic fibrosis, which results in a flood of blood spotted filters sent to our Centre only for the purpose of checking for the $\Delta F 508$ mutation.

Another major problem, closely linked with the former one, is the very limited application of large scale screening programmes for PKU, galactosaemia, and hypothyroidism and a complete absence of newborn screening for $\mathrm{CF}$ (immunoreactive trypsin test).

The absence of national and even local uniform regional registers of genetic diseases accessible for computer analysis is another serious obstacle to the active search and proper counselling of at risk families. Some promising attempts to create corresponding automated registers of inherited diseases have been undertaken in the Research Institute of Paediatrics and Child Surgery (Moscow), the Institute of Medical Genetics (Moscow), and the Institute for Physician Promotion and Training (Moscow). An automated national register incorporating information from many relevant local registers and accessible to medical geneticists in molecular diagnostic laboratories is an urgent need of medical genetic services in this country.

The clear advances in molecular studies of genetic diseases in Russia, especially in recent years, are largely the result of the close international contact of the above mentioned medical genetics groups with their colleagues in western Europe and the USA. The present critical political and economic situation in our country, with its effects on medical genetics, cannot last forever. With the constant support of our western colleagues and increasing opportunities for collaborative research projects, medical geneticists in Russia will do their best to survive and to surmount this difficult period in our history with as few losses as possible.

I wish to acknowledge our close and fruitful scientific contacts with colleagues in the UK. Besides the names mentioned throughout this review, I am personally grateful to Professors J Edwards and E Southern (Oxford), Professors $M$ Bobrow and P Goodfellow (London), Professor M Ferguson-Smith (Cambridge), and Professor Peter Harper, whose generous help and constant interest in the work of my colleagues and myself have had a major impact on advances in molecular diagnosis of genetic diseases in Russia and the former USSR as a whole. Wholehearted assistance of many other prominent scientists in medical genetics throughout the world and especially in the USA should also be mentioned. Financial support of the Wellcome Trust to many of our geneticists, especially to O Evgrafov, V Makarov, and the author, is highly appreciated.

1 Baranov VS, Ivaschenko TE, Gorbunova VN, et al. Allelic polymorphism of DNA loci closely linked to CF-gene in affected and non-affected persons from different populations of the USSR. Pediatr Pulmonol Suppl 1990;5:199200

2 Baranov VS, Ivaschenko TE, Gorbunova VN, et al. Frequency of the F508 deletion in cystic fibrosis patients from the European part of the USSR. Hum Genet 1991;87:61-4.

3 Schwartz EI, Khalchitsky SE, Eissensmith RC, Woo SLC. Polymerase chain-reaction amplification from dried blood spots on Guthrie cards. Lancet 1990;316:639-40.

4 Scriabin VN, Khalchitsky SE, Kuzmin SE, Kaboev OK, Kalinin VM, Schwartz EI. A crude lysate of cells immobilized on solid support serve as matrix for enzymatic DNA. Nucleic Acids Res 1990;18:4289. Baranov VS, Ivaschenko TE, Gorbunova VN, Osynovskaya
NS, Gembovskaya SA. Five years experience in molecu- 
lar analysis of cystic fibrosis in the USSR. Pediatr Pulmonol Suppl 1991;6:244.

6 Ivaschenko TE, Baranov VS, Dean M. Two new mutations and other CFTR gene molecular changes detected by SSCP analysis in CF-patients from Russia. Hum Genet (in press).

7 Ivaschenko TE, White MB, Dean M, Baranov VS. A deletion of two nucleotides in a Soviet family with cystic fibrosis causing early infant death. Genomics 1991;10:2989.

8 Baranov VS, Gorbunova VN, Ivaschenko TE, et al. Five years experience in prenatal diagnosis of cystic fibrosis in the USSR. Prenat Diagn 1992;12:575-86.

9 Voronina O, Gaitskhoki V, Potapova O, Gembytskaya T. Genetic heterogeneity of clinical forms of CF. Pediatr Pulmonol Suppl 1990;5:202.

10 Voronina O, Gaitskhoki V, Potapova O, Schwartz E, Kirukhina $\mathrm{L}$ Gembytskaya $\mathrm{T}$. Correlation of $\mathrm{F} 508$ deletion with CF clinical forms. Abstracts, 17th European Cystic with CF clinical forms. Abstracts, 17th

11 Kalinin VN, Trubnikova IS, Barbova NI, Kapranov NI. DelF508 mutation in cystic fibrosis in Moscow region.
Abstracts, 17th European Cystic Fibrosis Conference, Copenhagen, 1991:73.

2 Livshits LA, Kravchenko SA, Grishko VI, Gorovenko NG, Bujievskaya TI. Linkage disequilibrium between cystic fibrosis gene mutations and RFLP of human chromosome 7 within the Ukrainian population. Abstracts, 17th European Cystic Fibrosis Conference, Copenhagen, 1991:74.

13 Baranov VS, Gorbunova VN, Malysheva OV, et al. Dystrophin gene analysis and prenatal diagnosis of Duchenne phin gene analysis and prenatal diagnosis of (in press)

14 Abbs S, Yau S, Clark S, Mathew CG, Bobrow M. A convenient multiplex PCR system for the detection of
dystrophin gene deletions: a comparative analysis with dystrophin gene deletions: a comparative analysis with
cDNA hybridisation shows mistyping by both methods. $\mathcal{f}$ Med Genet 1991;28:304-11.

15 Roberts RG, Bentley DR, Barby TFM, Manners E, Bobrow M. Direct diagnosis of carriers of Duchenne and Becker muscular dystrophy by amplification of lymphocyte RNA. Lancet 1990;336:1523-6.

16 Surin VL, Zhukova EL, Solovyev GY, Grineva NI. Simple and convenient detection of a HindIII polymorphic site in intron 19 of factor VIII using PCR. Nucleic Acids Res 1990;18:3432.

17 Aseev MV, Malysheva OV, Baranov VS. Molecular analysis of some widespread X-linked diseases in different populations of the USSR. Abstracts, 8th International Congress of Human Genetics, 1991:182.

18 Wehnert M, Surin VL, Zhukova EL, Solovyev GY, Herrmann F. Prenatal diagnosis of hemophilia A by polymerase chain reaction (PCR) using Hind III polymorphism. Prenat Diagn 1990;10:529-32.

19 Kalinin VN, Laptev DA, Runkovskaya NG, Cotton RGH. Single base polymorphism in the coding region of the phenylalanine hydroxylase gene. Abstracts, European pociety of Human Genetics Annual Meeting, Leuven, BelSociety of Humat

20 Kalinin VN, Ramus S, Cotton RGH. Detection of the poin mutations by the limited elongation reaction method (LERM). Abstracts, European Society of Human Genetics Annual Meeting, Leuven, Belgium 1991:175.

21 Woo SLC, Okano Y, Dasovich M, et al. Multiple founding populations for phenylketonuria and prehistorical migration in Europe. Proc Natl Acad Sci USA (in press).

22 Schwartz EI, Goltzov AA, Kaboev OK, et al. A nove frame-shift mutation causing beta-thalassemia in Azerbaijan. Nucleic Acids Res 1989;17:3997.

23 Solovyev GY, Goltzov AA, Surin VL, et al. Molecular nature of mutations causing beta 0-thalassemia in Azerbaijan. Biomed Sci 1990;1:300-4.

24 Schwartzman AL, Gaitskhoki VS, L'vov VM, et al. Complex molecular structure of the gene coding for rat ceruloplasmin. Gene 1980;11:1-10.

25 Baranov VS, Schwartzman AL, Gorbunova VN, et al. Chromosomal localization of ceruloplasmin and transferrin genes in laboratory rats, mice and in man by hybridization with specific DNA probes. Chromosoma (Berl) 1987;96:60-6.

26 Shevtsov SP, Kuchinski AP, Kovalev YR, et al. Genetic study of predisposition to myocardium infarction. Abstracts, 8th International Congress of Human Genetics, 1991:203.

27 Schwartz EI, Shevtzov SP, Kuchinskas AK, et al. Ap proach to identification of a point mutation in apo-B100 gene by means of PCR mediated site directed mutagenesis. Nucleic Acids Res 1991;19:3752. 